\title{
In-Culture Selection and the Potential Effects of Changing Sex Ratios on the Reproductive Success of Multiannual Delayed Gametophytes of Saccharina latissima and Alaria esculenta
}

\author{
Alexander P. J. Ebbing ${ }^{1,2, * \mathbb{C}}$, Gregory S. Fivash ${ }^{1}$, Nuria B. Martin ${ }^{1}$, Ronald Pierik ${ }^{3} \oplus$, Tjeerd J. Bouma ${ }^{1}$, \\ Jacco C. Kromkamp ${ }^{1}$ and Klaas Timmermans ${ }^{1}$ (D) \\ 1 Department of Estuarine and Delta Systems, NIOZ Royal Netherlands Institute for Sea Research, P.O. Box 140, \\ 4401 NT Yerseke, The Netherlands; greg.fivash@nioz.nl (G.S.F.); nuria.bellido@hortimare.com (N.B.M.); \\ tjeerd.bouma@nioz.nl (T.J.B.); jacco.kromkamp@nioz.nl (J.C.K.); Klaas.Timmermans@nioz.nl (K.T.) \\ 2 Centre for Isotope Research (CIO)—Oceans, University of Groningen, P.O. Box 72, \\ 9700 AB Groningen, The Netherlands \\ 3 Department of Biology, Utrecht University, Padualaan 8, 3584 CH Utrecht, The Netherlands; r.pierik@uu.nl \\ * Correspondence: alexander.ebbing@nioz.nl
}

\section{check for} updates

Citation: Ebbing, A.P.J.; Fivash, G.S.; Martin, N.B.; Pierik, R.; Bouma, T.J.; Kromkamp, J.C.; Timmermans, K In-Culture Selection and the Potential Effects of Changing Sex Ratios on the Reproductive Success of Multiannual Delayed Gametophytes of Saccharina latissima and Alaria esculenta. J. Mar. Sci. Eng. 2021, 9, 1250. https:// doi.org/10.3390/jmse9111250

Academic Editor: Laurie Hofmann

Received: 24 September 2021

Accepted: 8 November 2021

Published: 11 November 2021

Publisher's Note: MDPI stays neutral with regard to jurisdictional claims in published maps and institutional affiliations.

Copyright: (c) 2021 by the authors. Licensee MDPI, Basel, Switzerland. This article is an open access article distributed under the terms and conditions of the Creative Commons Attribution (CC BY) license (https:// creativecommons.org/licenses/by/ $4.0 /)$.

\begin{abstract}
Multiannual delayed gametophyte cultures can stay vegetative for years, while also having the ability to grow. This study aims to investigate whether male and female multiannual delayed gametophyte strains of the species Saccharina latissima and Alaria esculenta grow at different rates in culture. We furthermore assessed how changing sex ratios can affect the reproductive yields of these cultures. The results indicate that the reproductive yield of cultures declines with decreasing male:female ratios, a correlation that becomes especially apparent at higher culture densities for both species. Female gametophyte densities in particular affected the observed reproductive yield of the cultures, with $S$. latissima cultures showing a clear reproductive optimum (sporophytes. $\mathrm{mL}^{-1}$ ) at $0.013 \mathrm{mg} \cdot \mathrm{mL}^{-1} \mathrm{DW}$ female gametophyte biomass, while the reproductive success of $A$. esculenta peaked at a density of $0.025 \mathrm{mg} \cdot \mathrm{mL}^{-1} \mathrm{DW}$ of female gametophyte biomass, after which the reproductive yield started to decline in both species. The results show that the sex ratio of a gametophyte culture is an important biotic life cycle control, with higher amounts of female gametophyte biomass halting gametophyte reproduction. Understanding how these changing sex ratios in gametophyte cultures affect reproduction is especially important in the aquaculture of kelp, where reliable preforming cultures are key to long-term success.
\end{abstract}

Keywords: delayed gametophytes; reproduction; gametophyte density; sporophytes; kelp aquaculture; life cycle controls; kelp; vegetative growth; biomass

\section{Introduction}

Interest in using delayed gametophytes as seed stock for large scale aquaculture of brown seaweeds is growing globally. The advantages of using delayed cultures are well understood [1]: (i) they can be kept healthy for prolonged periods of time [2-4], (ii) they can be successfully cryopreserved [5] and (iii) gametophyte cultures can easily be cloned [6]. These characteristics allow for the crossing of distantly related unialgal male and female gametophyte clone cultures, evoking hybrid vigor for future F1 hybrid cultivars [7-9]. However, in order to use these delayed gametophytes for large-scale aquaculture, we first need a detailed understanding of the controlled growth and reproduction of larger volumes of these delayed gametophyte cultures [10]. This is especially important for multiannual delayed (MAD) gametophytes, which are gametophytes that delayed their sexual reproduction by more than a year, thereby transgressing seasonally induced reproduction [11].

MAD gametophyte cultures can be subdivided into two distinctly different types of cultures. The first culture type is created from large amounts of extracted zoospores [12], 
contains both sexes [13] and is described in this study as "wildtype" cultures. Unialgal clonal cultures are the second culture type and start out from small, isolated gametophyte individuals that are bulked up through fragmentation into larger cultures [14], creating genetically identical clonal cultures [8]. The advantages of working with MAD clonal gametophytes instead of regular MAD wildtype cultures are both practical and scientific in nature. In practice, clonal cultures are less prone to biofouling and culture infections compared to wildtype cultures, making them more reliable to use in the long term. The reason why clonal cultures are less prone to fouling is because they start from individually isolated gametophytes [15]. In contrast, wildtype cultures start from zoospore extractions that inevitably come in contact with contaminated sorus material [12], increasing the chances for contamination in the long run. On a scientific level, the advantages of individually growing out clonal gametophytes allow us to optimize the vegetative growth of the gametophytes [16]. Using clonal cultures also allows us to manually change the genetic make-up of the gametophytes in the cultures, through clonal inclusion or exclusion for breeding purposes [9], or change the sex ratio [10]. Lastly, using unialgal clonal gametophyte cultures prevents in-culture selection from taking place, a process that occurs when conditions favor the growth of one genotype over another in genetically diverse cultures [17], such as wildtype gametophyte cultures.

Wildtype gametophyte cultures contain both male and female gametophytes, and when the sexes grow vegetatively at different rates, sexual in-culture selection can take place. For example, [18] showed that Laminaria digitata female gametophytes grow at a different rate than their male gametophyte counterparts, suggesting that over time the sex ratio of L. digitata wildtype cultures will change. Not just growth rates but also (a)biotic factors can change the sex ratio of a culture $[19,20]$, with the changing sex ratios inevitably altering the reproductive yield of a culture, since the contribution of the limiting sex in the production of offspring will diminish over time. To illustrate this, [10] showed that the sex ratio in Saccharina japonica cultures affected the reproductive yield of a culture, with decreasing male:female ratios corresponding to decreasing sporophytes being formed.

This study aims to investigate whether male and female multiannual delayed gametophyte strains grow at different rates in culture. We furthermore separately look into how changing sex ratios affect the reproductive success rates (sporophytes $\cdot \mathrm{mL}^{-1}$ ) of MAD S. latissima and A. esculenta gametophyte cultures over time. We hypothesize that the sex ratio of the cultures can have a strong influence on the reproductive success rates of MAD gametophytes, with overarching similarities between S. latissima and A. esculenta. Sexspecific clonal gametophytes are calibrated against Chlorophyll-a in order to quantitatively allow the comparison for interspecific reproductive yields along gradients of sex-specific gametophyte biomass. This ultimately allowed us to group the results of the two species together to assess whether the influence of changing sex ratios on the reproductive yield functions similarly in both species, proposing a common trait within the Laminariaceae.

\section{Material and Methods}

\subsection{Cell Culture and Maintenance}

Ripe Saccharina latissima sorus of 6 individuals from Leknesund, Norway (61.212994, $4.896644^{\circ}$ E) and Alaria esculenta sorus of 8 individuals from Fuhreholmen, Norway $\left(61.043292,4.868790^{\circ} \mathrm{E}\right)$, were collected and pooled in 2016. The release of zoospores was performed in the Netherlands, using a standard extraction protocol (protocol of [21], similar to earlier methods described by [22,23]). Zoospores were isolated from the culture to set up clean clonal cultures, separating the sexes. The medium of the multiannual delayed (MAD) clonal cultures used in this experiment was refreshed once every other month with $\mathrm{f} / 2$ medium [24] and the cultures grew vegetatively for approx. 2.5 years prior to the start of this experiment $\left(11^{\circ} \mathrm{C} ; 5 \mu \mathrm{mol} \cdot \mathrm{m}^{-2} \cdot \mathrm{s}^{-1}\right.$ photons of red light; $12: 12$ light:dark cycle). Isolated clonal gametophytes initially started out in small Petri dishes, and we eventually placed the clonal cultures in $2 \mathrm{~L}$ plastic barrels with filtered airlift systems when the gametophyte biomass became more voluminous. The sex-specific clonal cultures used 
here consisted of six individual clonal lines of the same sex that were grouped together. All clonal gametophytes were initially isolated from the same wildtype cultures of 6 (S. latissima) to 8 (A. esculenta) grouped individual motherplants. We grouped multiple clonal cultures together to increase the genetic diversity of the cultures, emulating the genetic diversity of wildtype cultures by relying less on gametophytes on the individual level.

\subsection{Gametophyte Biomass Calibration}

We used fluorometry measurements (Fast Ocean/Act2 FRRF, Chelsea Technologies Group Ltd., Surrey, UK) to assess the Chl-a concentration [Chl-a] of the cultures. Assessing gametophyte biomass is similar to the process of assessing phytoplankton, where Chl-a is used as a proxy for phytoplankton biomass [25]. These Chl-a concentrations were calibrated against the dry weight (DW) of freeze-dried gametophyte biomass of both S. latissima and A. esculenta clonal cultures. The gametophyte biomass needed to accurately calculate calibration lines was much higher (Figure 1) than the biomass needed for the assessment of the reproductive success rates, making it necessary for us to extrapolate the biomasses used in the well plates from the calibration lines. Caution is still needed with interpreting Chl-a as a proxy for biomass, since there could still be unknown interspecific differences, and chlorophyll content might possibly differ between individual gametophytes in ways we do not yet understand.

\subsection{The Vegetative Growth of Clonal Gametophyte Biomass}

The biomass $\left(\mathrm{mg} \cdot \mathrm{mL}^{-1}\right)$ of sex-specific clonal gametophyte cultures, consisting of the six pooled clonal gametophytes of S. latissima and A. esculenta, grown in $2 \mathrm{~L}$ aerated bottles, was measured over a time period of 21 days, in triplicate, under stock conditions $\left(8 \mu \mathrm{mol} \cdot \mathrm{m}^{-2} \cdot \mathrm{s}^{-1}\right.$ photons of red light; $1{ }^{\circ} \mathrm{C} ; 12: 12$ light:day cycle) using $\mathrm{f} / 2$ medium [24]. The initial culture density was relatively low $\left(\sim 0.2 \mathrm{mg} \cdot \mathrm{mL}^{-1} \mathrm{DW}\right)$ and culture medium was refreshed daily, thereby limiting negative effects of space, light and nutrient limitation.

\subsection{Gametophyte Reproduction}

The sexual reproduction of the pooled clonal gametophytes cultures was induced after homogenization, using $30 \mu \mathrm{mol} \cdot \mathrm{m}^{-2} \cdot \mathrm{s}^{-1}$ photons of white light $\left(11^{\circ} \mathrm{C} ; 12: 12\right.$ light:day cycle), with $\mathrm{f} / 2$ medium [24], using a gradient of gametophyte biomass density (0.004$\left.0.55 \mathrm{mg} \cdot \mathrm{mL}^{-1} \mathrm{DW}\right)$. Successful reproduction, i.e., number of regular-looking young sporophytes $(\geq 25 \mu \mathrm{m})$ per $\mathrm{mL}$, was determined using an inverted microscope $(40 \times$ magnification), 28 days after starting the induction for sexual reproduction. Each treatment $(\mathrm{N}=30)$ was performed in triplicate, placed in a well of a 96-well plate $(0.3 \mathrm{~mL})$, culture medium was not refreshed and all the young sporophytes were counted in each well. After 28 days, all fertilized eggs developed into small sporophytes that were reliably countable, with unfertilized eggs remaining as eggs. Cultures with different sex ratios were manually created to assess the influence of sex ratio on the reproductive yield of a culture (Table 1). The five ratios were specifically chosen to cover the entire male:female ratio spectrum using approximately equal steps.

Table 1. The ratios of male:female biomass used in the experiments, which are further described in Figures 2 and 3.

\begin{tabular}{cc}
\hline Male Gametophyte Biomass (\%) & Female Gametophyte Biomass (\%) \\
\hline 5 & 95 \\
25 & 75 \\
50 & 50 \\
75 & 25 \\
95 & 5 \\
\hline
\end{tabular}



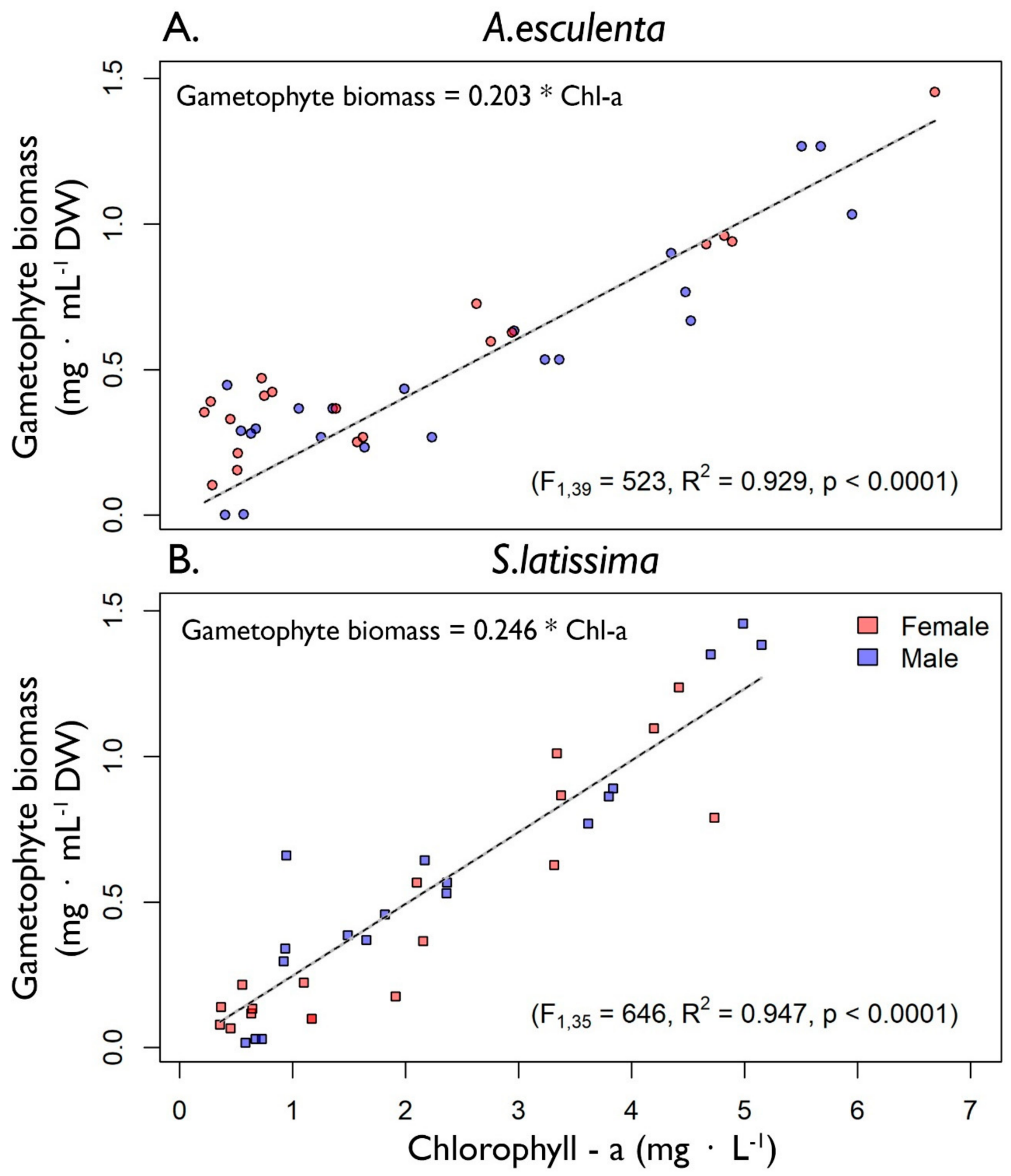

Figure 1. Chlorophyll a concentration $\left(\mathrm{mg} \cdot \mathrm{L}^{-1} \mathrm{Chl}\right.$; $\mathrm{x}$-axis) versus initial gametophyte density $\left(\mathrm{mg} \cdot \mathrm{mL}^{-1} \mathrm{DW}\right.$; yaxis) of A. esculenta (A) and S. latissima $(\mathbf{B})$ and the corresponding calibration lines. 


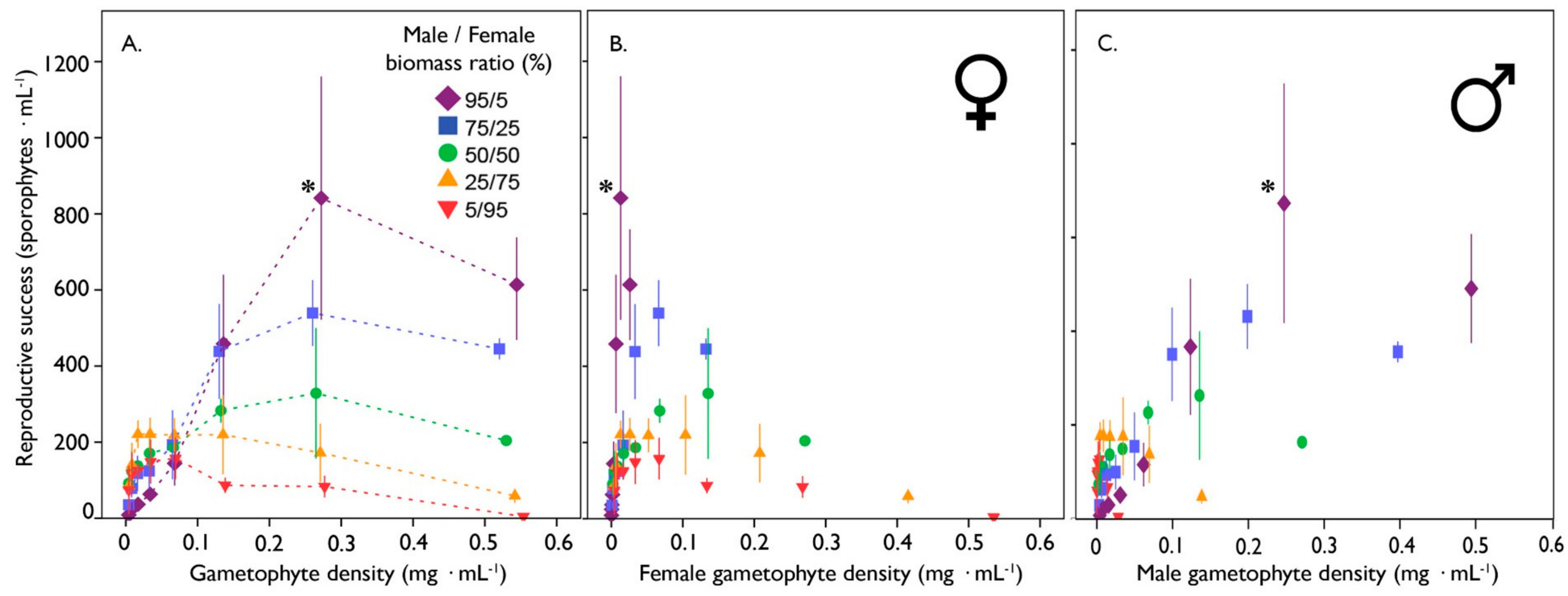

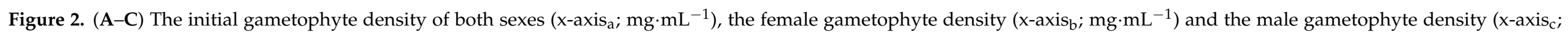

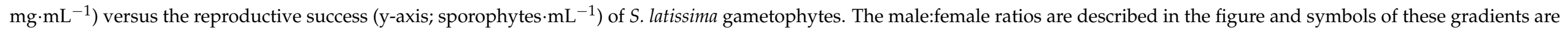

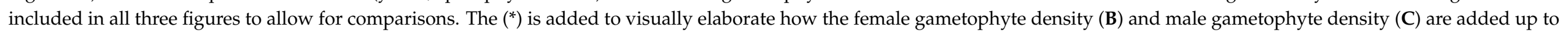
form gametophyte density (A). Linear interpolation lines are added in A for added readability. Values are expressed as mean $\pm \mathrm{SD}, n=3$. 


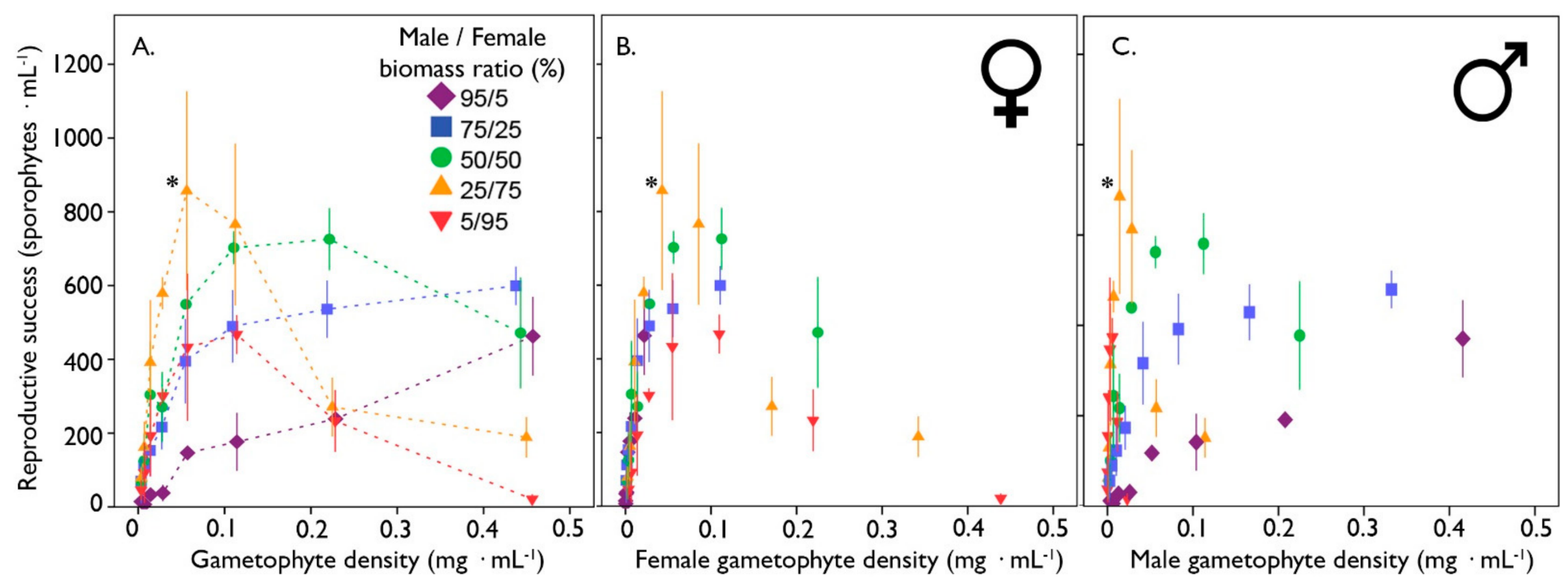

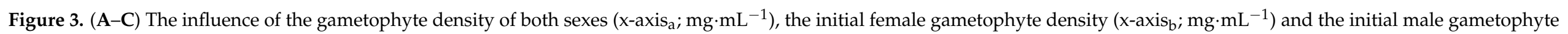

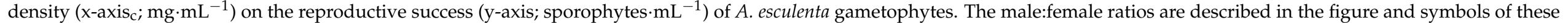

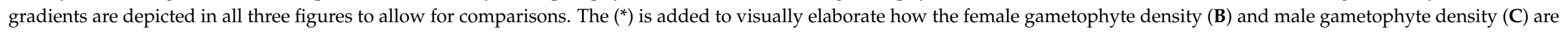
added up to form gametophyte density (A). Values are expressed as mean $\pm \mathrm{SD}, n=3$. 


\subsection{Statistical Analysis}

All statistical analysis was performed using SPSS 20.0.0 statistical package (SPSS Inc. Chicago, IL, USA). All data were normally distributed and analyzed for homogeneity using the Levene's test of variance. In case of unequal variances, a robust test of equality of means for unequal variances was applied (Welch $t$-test). If the data were found to be homogeneous, a one-way ANOVA was applied. Independent sample t-tests were used to assess whether biomass accumulation was significant or not (Figure 4). The Levene's test for equal variances was also applied here in every analysis, and the statistical results are interpreted accordingly (Table S1). The regressions that are described in Figures 1 and 5 were calculated using $\mathrm{R}$ version 3.6.0 [26]. Data of the reproductive success of the gametophytes $(n=3)$ are presented as mean $\pm \mathrm{SD}$.

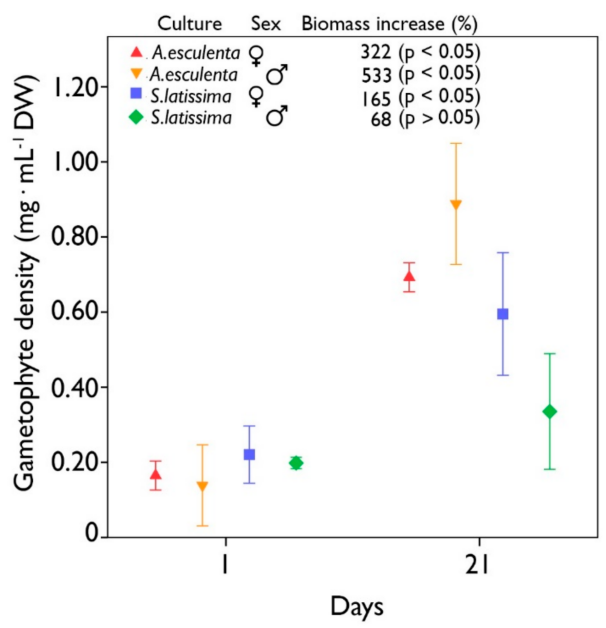

Figure 4. Gametophyte densities of a pool of six clonal male and female cultures of S. latissima and A. esculenta (mg. $\left.\mathrm{mL}^{-1} \mathrm{DW}\right)$ on day 1 and on day 21 . Culture symbols, sex and biomass increase (\%) are depicted in the figure. Values are expressed as mean $\pm \mathrm{SD}, n=3$.

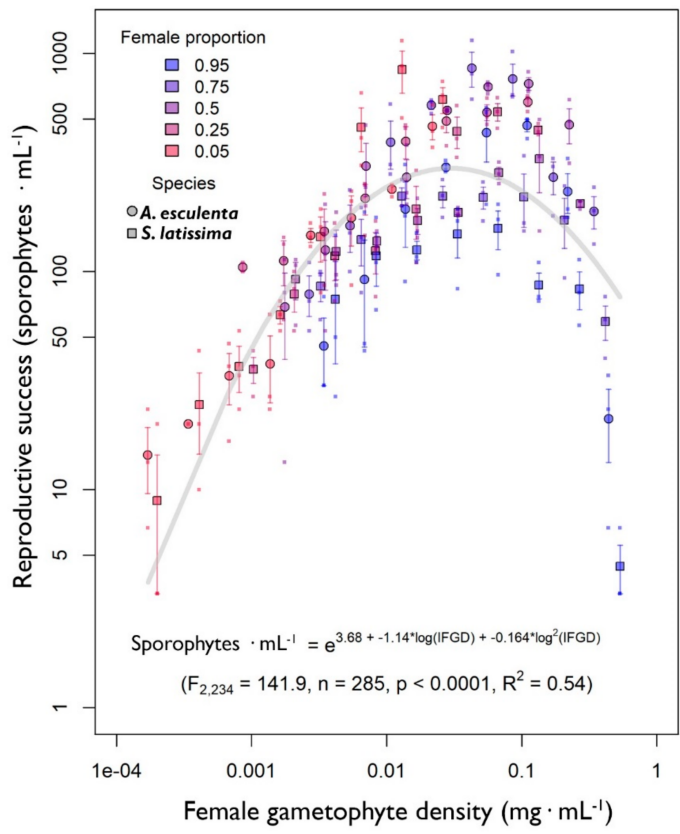

Figure 5. The female gametophyte density (x-axis, $\mathrm{mg} \cdot \mathrm{mL}^{-1}$ ) of S. latissima $(\square)$ and A. esculenta $(\bigcirc)$ versus the reproductive success (y-axis; sporophytes $\cdot \mathrm{mL}^{-1}$ ) under different female gametophyte proportions. Both axes are log-log transformed and values are expressed as mean $\pm \mathrm{sd}, n=3$. The raw values are also displayed using smaller colored points. 


\section{Results}

\subsection{Gametophyte Biomass Calibrations}

The dry weight of gametophyte biomass $\left(\mathrm{mg} \cdot \mathrm{mL}^{-1}\right)$ was successfully calibrated against the measured chlorophyll-a content of the gametophytes for both S. latissima and A. esculenta (Figure 1). Combining male and female biomass within the two species resulted in a calibration line for S. latissima $\left(\mathrm{F}_{1,39}=523, \mathrm{R}^{2}=0.929, p<0.0001\right)$ and one for A. esculenta $\left(\mathrm{F}_{1,35}=646 \mathrm{R}^{2}=0.947, p<0.0001\right)$. Note that the calibration line of $S$. latissima culture was steeper than that of $A$. esculenta, indicating that, per $\mathrm{mg}$ of biomass, there is less chlorophyll-a present in the gametophyte (Figure 1).

\subsection{The Effect of Sex Ratio on Gametophyte Reproduction of S. latissima}

The male:female sex ratio had a significant effect on the reproductive success (sporophytes. $\mathrm{mL}^{-1}$ ) of S. latissima gametophytes (WELCH ANOVA, $\mathrm{F}_{4,55}=7.6, p<0.05$; Table $\mathrm{S} 2$ ). The female gametopyte density gradient showed optimum reproductive success (Figure 2B), with optimal reproduction of 841 sporophtyes $\mathrm{mL}^{-1}$ observed at a female gameophyte density of $0.013 \mathrm{mg} \cdot \mathrm{mL}^{-1}$. After this optimum, the reproductive success rates declined continuously to a minimum of three sporophtyes $\mathrm{mL}^{-1}$ at a female gametophyte density of $0.535 \mathrm{mg} \cdot \mathrm{mL}^{-1}$. Note that the positive trend between male biomass and reproductive success followed the male:female sex ratio rather than the male biomass alone (Figure 2C). Overall, the lower the male:female ratio was, the lower the reproductive success (Figure 2A), with a male:female ratio of 5:95 resulting in the overall lowest reproductive success rate observed.

\subsection{The Effect of Sex Ratio on Gametophyte Reproduction of A. Esculenta}

The male:female sex ratio had a significant effect on the reproductive success (sporophytes. $\mathrm{mL}^{-1}$ ) of $A$. esculenta gametophytes (WELCH ANOVA, $\mathrm{F}_{4,57}=7.5, p<0.05$; Table S3). The reproductive success rates increased with decreasing male:female ratios (Figure 3A), with an reproductive optimum at a male:female ratio of 25:75 with a reproductive success rate of 856 sporophytes $\mathrm{mL}^{-1}$, after which reproduction showed a downward trend. Looking only at female gametophyte density, the reproductive optimum was observed at $0.025 \mathrm{mg} \cdot \mathrm{mL}^{-1}$ (Figure 3B). After this optimum, the reproductive success rates declined continuously to a minimum of 49 sporophtyes $\mathrm{mL}^{-1}$ at a female gameotphyte density of $0.42 \mathrm{mg} \cdot \mathrm{mL}^{-1}$, independent of male gametophyte biomass (Figure $3 \mathrm{C}$ ).

\subsection{Gametophyte Growth over Time}

The A. esculenta female culture (independent samples $t$-test, $\mathrm{t}(4)=-16.7, p<0.05$ ), A. esculenta male cultures $(\mathrm{t}(4)=6.5, p<0.05)$ and female $S$. latissima cultures $(\mathrm{t}(4)=-3.5$, $p<0.05$ ) all grew significantly in biomass (Table S1). The male $S$. latissima cultures did not show significant increases in biomass $(\mathrm{t}(4)=-1.5, p>0.05)$. Mean male A. esculenta biomass increased by $322 \%$ and mean female biomass was $533 \%$ above the initial biomass over a period of 21 days. The biomass increase in female S. latissima cultures was 165\% above the initial biomass, while the male $S$. latissima cultures grew the least of all cultures, with an average biomass increase of $68 \%$ above the initial biomass (Figure 4 ).

\subsection{The Effect of Female Gametophyte Biomass Density on Gametophyte Reproduction}

The effects of female gametophyte density on the reproductive success (sporophytes $\mathrm{mL}^{-1}$ ) of both S. latissima and A. esculenta are grouped in Figure 5. A second-order polynomial was fitted though the datapoints $\left(\mathrm{F}_{2,234}=141.9, \mathrm{R}^{2}=0.54, n=285, p<0.0001\right)$ to predict the number of sporophytes $\mathrm{mL}^{-1}$, independent of species, male biomass or sex ratio, that can be formed, depending on the female gametophyte density $\left(\mathrm{mg} \cdot \mathrm{mL}^{-1}\right)$, independent of the species considered. Peak reproductive success was calculated to be at $0.019 \mathrm{mg} \cdot \mathrm{mL}^{-1}$ for female gametophyte DW. 


\section{Discussion}

Our study of sex ratio-specific reproduction in multiannual delayed (MAD) S. latissima and A. esculenta gametophyte cultures showed that in-culture selection can potentially take place due to different growth rates between the sexes. The calibration lines in Figure 1 made it possible to visually compare sex-specific gametophyte growth rates by showing that the conversion between Chl-a and dry weight gametophyte biomass was indistinguishable between the sexes $\left(R^{2}>0.92\right)$. Figure 4 strongly suggests that different growth rates between the sexes takes place, which is subsequently backed by other studies with more thorough datasets for S. latissima and A. esculenta [27], as well as Laminaria digitata [18]. Note that the limited number of replicates and short time span of only 21 days exemplify the fact that the experiment was not initially set up to search for different growth rates between the sexes. In a separate experiment, we showed that skewed sex ratios, hypothetically resulting from the faster growth of a particular sex, could affect the reproductive yield of cultures over time. Skewed male:female ratios turn out to be important biotic factors for the reproductive yield of MAD gametophyte cultures. In particular, the amount of female gametophyte biomass appeared to be instrumental in the reproductive success rates obtained in both S. latissima and A. esculenta cultures. Clear reproductive optima were visible in both species, with optimal reproductive success at female gametophyte densities of $0.013 \mathrm{mg} \cdot \mathrm{mL}^{-1}$ (S. latissima) and $0.025 \mathrm{mg} \cdot \mathrm{mL}^{-1}$ (A. esculenta), respectively, independent of the amount of male biomass that was added. Increasing female biomass beyond these optima resulted in declining reproductive yields. This inverse correlation between gametophyte reproduction and culture density agrees with previous studies that used either zoospores $[13,28]$ or wildtype gametophyte cultures [29]. Lastly, plotting female gametophyte density of both $S$. latissima and A. esculenta together leads to similarities between the two species $\left(R^{2}=0.54\right.$; Figure 5). These interspecific similarities between the reproductive success rate of a culture and female gametophyte density point towards a common driver influencing sex ratiodependent reproduction within the family of the Laminariaceae.

What the driving force is behind the correlation between culture density, in particular female gametophyte density, and the observed reproductive yields remains unclear. Putative density-associated nutrient deficiency is sometimes offered as an explanation [23,30]. However, [21] showed that the interaction between gametophyte density and reproduction was not due to nutrient availability but could also directly be correlated with the density of the culture itself. The next logical step was to assess whether male or female gametophyte biomass was instrumental to this apparent correlation. For illustration, [10] experimented with different ratios of delayed male and female $S$. japonica gametophytes, and had similar results as described in our study. They found decreasing reproductive success rates with increased female proportions, which were attributed to the decreased availability of male gametophytes in the culture. Decreased availability of male gametophyte biomass does, however, not explain our findings, since decreasing male biomass did not directly translate to decreased reproductive success, something that was especially apparent in A. esculenta cultures (Figure 3C). What is clear from both species is that the reproductive optimum was strongly female density-dependent, since optimal reproductive yields always approximated the same female densities, independent of male addition (Figures $2 B$ and $3 C$ ). The influence of female biomass is especially apparent in Figure 2C, where the increase in $S$. latissima reproductive yields primarily follows the sex ratio that was used and not the absolute contribution of male gametophyte biomass. Although the reproductive trends are similar in both species, as is shown in Figure 5, the reproductive success rates are not completely interchangeable between the species. For example, the optimal female density in A. esculenta $\left(0.025 \mathrm{mg} \cdot \mathrm{mL}^{-1}\right)$ and S. latissima $\left(0.013 \mathrm{mg} \cdot \mathrm{mL}^{-1}\right)$ might seem similar at first glance, but the optimal density for A. esculenta is still almost double that of S. latissima. Another apparent difference between the species is the specific sex ratio where optimal reproduction was achieved, with an optimal male:female ratio of 95:5 in S. latissima, while in A. esculenta, the optimal male:female ratio was at 25:75. What the driving force is for these differences is not clear, but can be species-specific, culture-specific or as a result of factors 
that are not yet understood. The interspecific differences can also lie in characteristics that were simply not quantified during this experiment, such as sex-specific gametophyte cell counts, total egg production, sperm production, sperm activity or gametophyte health.

The overarching similarity between the two species appears to revolve around how female biomass density affects reproductive yield (Figure 5). Whether the observed densitydependent reproduction is affected by physical obstruction of the female gametophytes (e.g., obstructing sperm movement) or because of other (a) biotic factors (e.g., hormones) is not yet known. It is clear that more research is needed on the life cycle controls affecting delayed gametophytes, as it is becoming clear that delayed gametophytes behave differently than their non-delayed counterparts [29]. These artificial culture environments allow for biotic factors to become important novel life cycle controls [11]. Our current study shows that female gametophyte biomass plays a central role in the observed inverse correlation between culture density and gametophyte reproduction, and that different growth rates between the sexes can change the contribution of female gametophytes over time. The fact that the sexes can grow at different rates [18,27], thereby changing the sex ratios of a culture over time, altering the reproductive yields of cultures, has major ramifications for seaweed aquaculture. Nonetheless, more studies are needed, especially those focusing on wildtype cultures, since the six strains of clonal gametophytes per gender that are used here may not represent the general output of the species.

Understanding the phenomenon of in-culture selection is essential in the aquaculture of kelp, especially for farmers who aim to use the controlled reproductive method as their primary cultivation method [11], since this method primarily uses MAD gametophytes as seed stock for their farms [10]. These farmers are dependent on large quantities of healthy sporophytes that can reliably be produced from their own gametophyte stock cultures [22]. Unreliable and especially underperforming gametophyte cultures can turn out to be damaging to a seaweed farmer, since lower reproductive success rates automatically translate to lower sporophyte counts to sow, adding unwanted insecurities during an already hectic planting season. A solution to this problem is to grow out male and female gametophyte cultures separately, since this opens up the possibility of directly controlling the sex ratio prior to the induction of gametophyte reproduction, preventing unwanted in-culture selection and opening up new ways to optimize the reproductive yields of MAD gametophyte cultures. Sex separation can be performed practically by growing out male and female gametophyte lines within separate bioreactors [27]. More research is needed to understand how MAD gametophyte cultures change through time, and how the impact of this translates towards large scale seaweed industry.

Supplementary Materials: The following are available online at https:/ / www.mdpi.com/article/ 10.3390/jmse9111250/s1, Tabel S1; Independent Samples T-test to test the difference between the biomasses on day 1 compared to the biomasses on day 21 for S. latissima and A. esculenta male and female gametophyte cultures. Table S2; Robust test of variance for the effects of sex ratio on the reproductive success of $S$. latissima gametophytes (Figure 2; Welch ANOVA), after not passing the test of homogeneity of variances. Table S3; Robust test of variance for the effects of sex ratio on the reproductive success of A. esculenta gametophytes (Figure 3; Welch ANOVA), after not passing the test of homogeneity of variances.

Author Contributions: Conceptualization, A.P.J.E.; methodology, A.P.J.E.; software, A.P.J.E. and G.S.F.; validation, A.P.J.E. and K.T.; formal analysis, A.P.J.E., N.B.M. and G.S.F.; investigation, A.P.J.E. and N.B.M.; resources, K.T.; data curation, A.P.J.E. and G.S.F.; writing-original draft preparation, A.P.J.E.; writing-review and editing, A.P.J.E.; visualization, A.P.J.E. and G.S.F.; supervision, G.S.F., R.P., T.J.B., J.C.K. and K.T.; project administration, K.T.; funding acquisition, K.T. All authors have read and agreed to the published version of the manuscript.

Funding: This research received no external funding.

Data Availability Statement: Data obtained in the experiments herein can be available upon request at the NIOZ repository (www.nioz.nl).

Conflicts of Interest: The authors declare no conflict of interest. 


\section{References}

1. Goecke, F.; Klemetsdal, G. Ergon, Åshild Cultivar Development of Kelps for Commercial Cultivation-Past Lessons and Future Prospects. Front. Mar. Sci. 2020, 8, 110. [CrossRef]

2. Barrento, S.; Camus, C.; Pinto, I.S.; Buschmann, A. Germplasm banking of the giant kelp: Our biological insurance in a changing environment. Algal Res. 2016, 13, 134-140. [CrossRef]

3. Carney, L.T. A MULTISPECIES LABORATORY ASSESSMENT OF RAPID SPOROPHYTE RECRUITMENT FROM DELAYED KELP GAMETOPHYTES1. J. Phycol. 2011, 47, 244-251. [CrossRef]

4. Wade, R.; Augyte, S.; Harden, M.; Nuzhdin, S.; Yarish, C.; Alberto, F. Macroalgal germplasm banking for conservation, food security, and industry. PLoS Biol. 2020, 18, e3000641. [CrossRef]

5. Visch, W.; Menéndez, C.R.; Nylund, G.M.; Pavia, H.; Ryan, M.; Day, J. Underpinning the Development of Seaweed Biotechnology: Cryopreservation of Brown Algae (Saccharina latissima) Gametophytes. Biopreserv. Biobank. 2019, 17, 378-386. [CrossRef]

6. Reddy, C.R.K.; Jha, B.; Fujita, Y.; Ohno, M. Seaweed micropropagation techniques and their potentials: An overview. Environ. Boil. Fishes 2007, 20, 609-617. [CrossRef]

7. Shan, T.F.; Pang, S.J.; Li, J.; Gao, S.Q. Breeding of an elite cultivar Haibao No. 1 of Undaria pinnatifida (Phaeophyceae) through gametophyte clone crossing and consecutive selection. Environ. Boil. Fishes 2016, 28, 2419-2426. [CrossRef]

8. Zhao, X.B.; Pang, S.J.; Liu, F.; Shan, T.F.; Li, J.; Gao, S.Q.; Kim, H.G. Intraspecific crossing of Saccharina japonica using distantly related unialgal gametophytes benefits kelp farming by improving blade quality and productivity at Sanggou Bay, China. Environ. Boil. Fishes 2016, 28, 449-455. [CrossRef]

9. Martins, N.; Pearson, G.A.; Gouveia, L.; Tavares, A.I.; Serrão, E.A.; Bartsch, I. Hybrid vigour for thermal tolerance in hybrids between the allopatric kelps Laminaria digitata and L. pallida (Laminariales, Phaeophyceae) with contrasting thermal affinities. Eur. J. Phycol. 2019, 54, 548-561. [CrossRef]

10. Zhang, Q.S.; Qu, S.C.; Cong, Y.Z.; Luo, S.J.; Tang, X.X. High throughput culture and gametogenesis induction of Laminaria japonica gametophyte clones. Environ. Boil. Fishes 2008, 20, 205-211. [CrossRef]

11. Ebbing, A.P.J.; Pierik, R.; Fivash, G.S.; van de Loosdrecht, N.C.; Bouma, T.J.; Kromkamp, J.C.; Timmermans, K. The role of seasonality in reproduction of multiannual delayed gametophytes of Saccharina latissima. J. Phycol. 2021, 57, 1580-1589. [CrossRef]

12. Alsuwaiyan, N.A.; Mohring, M.B.; Cambridge, M.; Coleman, M.A.; Kendrick, G.A.; Wernberg, T. A review of protocols for the experimental release of kelp (Laminariales) zoospores. Ecol. Evol. 2019, 9, 8387-8398. [CrossRef]

13. Gil Choi, H.; Kim, Y.S.; Lee, S.J.; Park, E.J.; Nam, K.W. Effects of daylength, irradiance and settlement density on the growth and reproduction of Undaria pinnatifida gametophytes. Environ. Boil. Fishes 2005, 17, 423-430. [CrossRef]

14. Wu, C.; Li, D.; Liu, H.; Peng, G.; Liu, J. Mass culture of Undaria gametophyte clones and their use in sporeling culture. Hydrobiologia 2004, 512, 153-156. [CrossRef]

15. Li, D.; Zhou, Z.-G.; Liu, H.; Wu, C. A new method of Laminaria japonica strain selection and sporeling raising by the use of gametophyte clones. Hydrobiologia 1999, 398/399, 473-476. [CrossRef]

16. Zhang, Y.; Zhang, Y.; Li, M.; Li, L.; Tang, X.; Gao, J. Homogenization significantly enhances growth of macroalga Saccharina japonica female gametophytes. Algal Res. 2019, 43, 101640. [CrossRef]

17. Lakeman, M.B.; von Dassow, P.; Cattolico, R.A. The strain concept in phytoplankton ecology. Harmful Algae 2009, 8, 746-758. [CrossRef]

18. Destombe, C.; Oppliger, L.V. Male gametophyte fragmentation in laminaria digitata: A life history strategy to enhance reproductive success. Cah. De Biol. Mar. 2011, 52, 385-394.

19. Oppliger, L.V.; Correa, J.A.; Engelen, A.; Tellier, F.; Vieira, V.; Faugeron, S.; Valero, M.; Gomez, G.; Destombe, C. Temperature Effects on Gametophyte Life-History Traits and Geographic Distribution of Two Cryptic Kelp Species. PLoS ONE 2012, 7, e39289. [CrossRef]

20. Murúa, P.; Patiño, D.J.; Müller, D.G.; Westermeier, R. Sexual compatibility in giant kelp gametophytes: Inter-cultivar hybridization is average between parents but excels under harsher conditions. Environ. Boil. Fishes 2021, 33, 3261-3275. [CrossRef]

21. Ebbing, A.; Pierik, R.; Bouma, T.; Kromkamp, J.C.; Timmermans, K. How light and biomass density influence the reproduction of delayed Saccharina latissima gametophytes (Phaeophyceae). J. Phycol. 2020, 56, 709-718. [CrossRef]

22. Redmond, S.; Green, L.; Yarish, C.; Kim, J.; Neefus, C. New England Seaweed Culture Handbook. Seaweed Cultiv. 2014. [CrossRef]

23. Bartsch, I. Derivation of clonal stock cultures and hybridization of kelps: A tool for strain preservation and breeding programs. In Protocols for Macroalgae Research; Charrier, B., Wichard, T., Reddy, C.R.K., Eds.; CRC Press: Boca Raton, FL, USA; Taylor \& Francis Group: New York, NY, USA, 2018.

24. Guillard, R.R.L.; Ryther, J.H. Studies of marine planktonic diatoms. I. Cyclotellanana Hustedt and Detonula Confervacea (cleve). Can. J. Microbiol. 1962, 8, 229-239. [CrossRef] [PubMed]

25. Huot, Y.; Babin, M.; Bruyant, F.; Grob, C.; Twardowski, T.H.; Claustre, H. Does chlorophyll a provide the best index of phytoplankton biomass for primary productivity studies? Biogeosci. Discuss. 2007, 4, 707-745. [CrossRef]

26. Team R Core. R: A Language and Environment for Statistical Computing; Team R Core: Vienna, Austria, 2018; Available online: https: / / www.r-project.org/ (accessed on 4 March 2021). 
27. Ebbing, A.; Fivash, G.; Pierik, R.; Bouma, T.; Kromkamp, J.C.; Timmermans, K. The SeaCoRe system for large scale kelp aquaculture: A plug-and-play, compatible, open-source system for the propagation and transport of clonal gametophyte cultures. J. Appl. Phycol. 2021. [CrossRef]

28. Reed, D.C. The Effects of Variable Settlement and Early Competition on Patterns of Kelp Recruitment. Ecology 1990, 71, 776-787. [CrossRef]

29. Carney, L.T.; Edwards, M.S. Role of nutrient fluctuations and delayed development in gametophyte reproduction by Macrocystis pyrifera (Phaeophyceae) in southern California. J. Phycol. 2010, 46, 987-996. [CrossRef]

30. Reed, D.C.; Neushul, M.; Ebeling, A.W. Role of Settlement Density on Gametophyte Growth and Reproduction in the Kelps Pterygophora Californica and Macrocystis pyrifera (Phaeophyceae). J. Phycol. 1991, 27, 361-366. [CrossRef] 